социология

21 марта 2015 г. на кафедре социологии Московского гуманитарного университета в рамках работы научной школы социологии молодежи состоялся круглый стол «Молодежь в зеркале социологии». Традиция апробации результатов исследования преподавателей кафедры, аспирантов и активного их обсуждения на кафедре существует уже около 10 лет. Публикуем в рубрике материалы данного круглого стола.

DOI: 10.17805/trudy.2015.4.3

\title{
ЗНАНИЕ, УМЕНИЯ И НАВЫКИ КАК ЭЛЕМЕНТЫ ОБРАЗОВАТЕЛЬНОГО ОПЫТА МОЛОДЕЖИ
}

\author{
Н. А. Селиверстова \\ (Московский гуманитарный университет)
}

Аннотация: В статье анализируются знания, умения, навыки как элементы образовательного опыта молодежи, рассматривается возможность исследования образовательного опыта на эмпирическом уровне.

Ключевые слова: знания, умения, навыки, образовательное знание, симулякры знаний, образовательный опыт, учащаяся молодежь.

\section{KNOWLEDGE, ABILTIES AND SKILLS AS CONSTITUENT ELEMENTS OF EDUCATIONAL EXPERIENCE OF THE YOUNG}

\author{
N. A. Seliverstova \\ (Moscow University for the Humanities)
}

Abstract: The article looks at the knowledge, abilities and skills of the young as elements of their educational experience. We also discuss whether it is possible to study this form of experience on the empirical level.

Keywords: knowledge, abilities, skills, educational knowledge, knowledge simulacra, educational experience, student youth.

Знание, умения и навыки - составляющие ядра образовательного опыта наряду с переживаниями, обусловленными взаимодействиями с учителями, учениками, группой учеников по поводу знаний (Селиверстова, 2015). Цель настоящей статьи - более детальное рассмотрение названных элементов образовательного опыта применительно к учащейся молодежи.

Трактовки понятия «знание» в социологии составляют солидное множество. Нас трактовки понятия «знание» интересуют в связи с образованием молодежи, но без исходных понятий не обойтись. 
Интерпретация понятия «знание» в широком смысле как знание законов природы, знание знаков и символов вообще, приобретенные из учебников или научных книг позволяет утверждать, что им владеют в той или иной степени большинство людей (Москвичев, 2009а: 73). В узком смысле это знание, полученное научными методами, обоснованное логически и (или) экспериментально, в том числе практикой, знание, организованное в некоторую систему и способное к передаче другим через средства коммуникации. Такие знания получают в процессе образования. В полном объеме такие знания получить в процессе образования нельзя, коли речь идет об элементах такого знания. Объем таких знаний определяется уровнем образования (Москвичев, 2009b: 77).

В данном контексте вспоминается одна из лекций Э. Гидденса, прочитанная в начале 1990-х гг. на Высших социологических курсах в Институте молодежи (ныне Московский гуманитарный университет), на которой он рассуждал о том, что доля знаний, полученных на основе личного опыта, не столь велика. При современном уровне развития науки, мы полагаемся на «экспертное» знание (именно так определил этот тип знания Гидденс) и в «базе данных» современного человека оно, по оценке исследователя, занимает большую часть.

Значительную долю экспертных или научных знаний, безусловно, подвергнутых обработке, мы получаем в образовательных организациях. Позиция Э. Гидденса явно восходит к феноменологии А. Шюца. А. Шюц акцентирует внимание на социальном происхождении большей части знаний. Среди тех, кто передает знания, нас интересуют «учителя и учителя моих учителей» (Шюц, 2004) как «эксперты», транслирующие знания, во многом личностно определяющие образовательный опыт учеников. Как известно, знание относится к социально распределяемым ресурсам. Резкая дифференциация российского общества по доходам уже на уровне дошкольного образования приводит к закреплению детей в образовательных организациях разной степени престижности и качества предлагаемых образовательных услуг. Кроме того, одно и то же знание осваивается обучающимися по-разному, в зависимости от их способностей. Это ведет к различиям в образовательном опыте индивида.

Очевидно, что в данном контексте речь идет об образовательном знании, которое отличается от научного и повседневного знаний. Г.Е.Зборовский анализирует образовательное знание с точки зрения его содержания, структуры, функций, участников трансляции, отношения к знанию (Зборовский, 2012). Он пишет, что научное знание в образовательном знании воспроизводится далеко не всей гаммой и палитрой понятий, терминов, суждений, умозаключений, гипотез. Его адаптируют для понимания аудитории, что и позволяет говорить о его упрощении. 
Однако в социально-гуманитарных науках возникает ситуация, когда научные и образовательные знания практически совпадают. Г.Е. Зборовский в качестве примера приводит социологическое знание, во многих учебниках и учебных пособиях для студентов-социологов излагается система непосредственно научного знания. Как правило, это учебные пособия по отраслям социологического знания. По мнению, Г. Е. Зборовского тождественность научного и образовательного знаний социологии обусловлена их схожей структурой. И в первом, и во втором знании содержатся представления, понятия, суждения, умозаключения, гипотезы, доказательства, социальные факты, явления процессы, проблемы. При этом полное или почти полное совпадение образовательного и научного знаний является показателем эффективности первого. Таким образом, образовательное знание социологии по Г. Е. Зборовскому, это еще и знание разделяемое педагогами и учащимися в привычной обстановке учебных занятий.

Состояние образовательного знания в конкретной науке определяется требованиями к нему со стороны его субъектов. Г. Зборовский совершенно справедливо пишет об ограниченности образовательного знания применительно к сфере социально-гуманитарного знания. Парадокс заключается в том, что к этому ведет активное использование информационных технологий студентами и школьниками как средства доступа к знаниям. И в этом особенность образовательных знаний значительной доли учащейся молодежи.

Понятие «образовательное знание» активно обсуждается в психологопедагогическом сообществе. Причем в условиях модернизации образования ставится вопрос о необходимости конструирования нового знания субъектом образовательной деятельности (не преподавателем, а выпускником любой школы) (Мухаметзянова Ф., Мухаметзянова Г., 2013: 95). Средством подобного проекта авторы называют образовательную рефлексию, интерпретируя данное понятие как «осмысление субъектом образовательной истории и разработку проекта собственного образования» (там же). Однако, сама субъектность как условие подобного проекта, заметим, к сожалению, присуща далеко не всем учащимся общеобразовательной и высшей школы. Повторим то, что уже формулировалось нами ранее. Недостаточный уровень базовых знаний не позволяет многим учащимся выступать субъектом образовательного процесса (Селиверстова, 2015).

Преобразование научного знания в процессе образования, по мнению данных авторов, требует рассмотрения процесса в контексте синергии (Мухаметзянова Ф., Мухаметзянова Г., 2013: 96). Образовательное знание в интерпретации Ф. Г. Мухаметзяновой и Г. В. Мухаметзяновой - это особый вид знания (но не эклективный симбиоз научного и обыденножитейского знания), это вид доступного знания, которое развивается у 
субъектов образовательной деятельности в процессе совместного творческого нахождения в контексте информационного образовательного пространства. Как только ставится вопрос о «доступном» знании для учащейся молодежи, это означает, что речь идет об его упрощении. Как и Г.Е. Зборовский, названные авторы подчеркивают, что это знание, разделяемое педагогами и обучающимися в обыденности информационного образовательного пространства. Это знание, «рождающееся» в процессе субъектно-ориентированного взаимодействия между научным, культурным и повседневным знанием или возникающее как синергийная взаимосвязь отдельных положений, фактов, суждений, теорий и концепций, рассуждений, оформленных в виде утверждений и, далее поступков в сознании и поведении субъектов образовательной деятельности (Мухаметзянова Ф., Мухаметзянова Г., 2013: 105).

В контексте образовательной политики рассматривает проблему знания И. М. Ильинский, результатом образования или «конечным смыслом образования», как он считает, выступает не знание, а понимание. Аргумент данной позиции убедителен: при существующих потоках информации наращивание только компонента знаний бессмысленно, необходимо учить пониманию. Он утверждает: «Вуз должен через знание развивать мышление до стадии понимания» (Ильинский, 2014: 10). Безусловно, в ситуации, когда знание имеет способность устаревать достаточно быстро, иногда к моменту окончания вуза, оно теряет ценность. Безусловную ценность приобретает способность уметь находить нужное знание, использовать его в соответствии с поставленными целями. Операционализация понятия «понимание» затруднительна для социологического эмпирического исследования. По сути, понимание может быть зафиксировано контрольно-измерительными материалами, если это, конечно, задание в форме какой-либо задачи / задания, а не обычного теста. Но это задача для учителя / преподавателя, а не для исследователя-эмпирика.

В этой связи важно затронуть еще один важный аспект понимания образовательного знания. Оно может быть ошибочным, искаженным в процессе восприятия. Однако все изложенное выше имеет отношение к норме или эталону. Социальная реальность такова, что правомерно вести речь об имитации производства, передачи и освоения знания (Латов, Ключарев, 2015). Очевидно, что образовательный опыт конкретных молодых людей будет содержать способы вполне легитимного получения дипломов о наличии квалификаций разных уровней профессионального образования и симулякры знаний, а не сами знания.

Что касается понятий «навыки» и «умения», то психологи рассматривают их как понятия, находящиеся в одном смысловом поле, но на разных уровнях. С. Рубинштейн включает в это поле еще и привычки. 
«Автоматизированные, сознательно, полусознательно и бессознательно контролируемые компоненты деятельности называются соответственно умениями, навыками и привычками. Умения - это элементы деятельности, позволяющие что-либо делать с высоким качеством, например, точно и правильно выполнять какое-либо действие, операцию, серию действий или операций (Рубинштейн, 1989: 10). В этом подходе навыки - это полностью автоматизированные, инстинктоподобные компоненты умений, реализуемые на уровне бессознательного контроля. Автоматизация действий и операций превращает их в навыки. По С. Рубинштейну, меняется структура деятельности: автоматизированные действия и операции сливаются в единый, целостно протекающий акт, именуемый умением (например, сложная система движений человека, пишущего текст, выполняющего спортивное упражнение, проводящего хирургическую операцию, изготавливающего тонкую деталь предмета, читающего лекцию и т. п.). При этом лишние, ненужные движения исчезают, а количество ошибочных резко падает. Контроль за действием или операцией при их автоматизации смещается с процесса на конечный результат, а внешний, сенсорный контроль замещается внутренним, про-приоцептивным. Скорость выполнения действия и операции резко возрастает, достигая некоторого оптимума или максимума (там же: 29). Понятно, что достичь умения в чем-либо можно регулярными упражнениями, тренировкой.

Другой психолог, Р. С. Немов, акцентирует внимание на том, что определенные знания, умения и навыки становятся целью учебной деятельности (Немов, 2003: 149). В отличие от навыков, умения образуются в результате координации навыков и они контролируемы. Другое различие, по Р. С. Немову, между навыками и умениями заключается в том, что человек способен изменять структуру умений посредством замены инструментов, средств, последовательности операций. Однако конечный результат всегда один. Активная интеллектуальная деятельность, сознательный интеллектуальный контроль и определяют иерархию в системе «навыки и умения», ставят умения на более высокий уровень по сравнению с навыками (там же). В типологии навыков и умений Р. С. Немова нас интересует большая часть: познавательные, теоретические и практические.

Как пишет Р. С. Немов, познавательные умения включают способности, связанные с поиском, восприятием, запоминанием и переработкой информации. Они соотносятся с основными психическими процессами и предполагают формирование знаний. Теоретические умения и навыки связаны с абстрактным интеллектом. Они выражаются в способности человека анализировать, обобщать материал, строить гипотезы, теории, производить перевод информации из одной знаковой системы в другую. Такие умения и навыки более всего проявляются в творческой работе, 
связанной с получением идеального продукта мысли (там же: 162). Практические навыки и умения складываются в различных упражнениях, и они важны для других типов навыков и упражнений.

Именно практические навыки и умения имеют безусловную ценность у прагматичных и практикоориентированных современных школьников и студентов. К сожалению, среди студентов среднестатистических вузов наблюдается тенденция к стремлению приобрести конкретный навык или умение без овладения теоретическим знанием.

По итогам проведенного анализа возникает естественный вопрос: как данные элементы образовательного опыта можно исследовать на эмпирическом уровне? Социолог на эмпирическом уровне может исследовать оценку знаний, навыков и умений, полученных в образовательных учреждениях и процессе самообразования. В случае необходимости их можно будет соотнести с конкретными учебными дисциплинами, очевидно с ограниченным кругом.

Можно предположить, что оценка образовательного опыта молодых людей во многом будет зависеть от того какие у него были учителя и соученики, и какие отношения между ними существовали, а, может быть, и не прервались после завершения формального образования.

\section{СПИСОК ЛИТЕРАТУРЫ}

Зборовский, Г. Е. (2012) Образовательное знание как проблема социологии // Социологические исследования. № 2. С. 12-20.

Ильинский, И. М. (2014) «Знание - понимание - умение» как формула перспективной научной и образовательной политики // Знание. Понимание. Умение. № 1. С. 5-17.

Латов, Ю. В., Ключарев, Г. А. (2015) Неформальные «правила игры» в образовательной системе: симуляция образования, симулякры и брокеры знаний // Общественные науки и современность. № 2. С. 31-41.

Москвичев, Л. Н. (2009а) Знание (1) // Тезаурус социологии: темат. слов.-справ. / под ред Ж. Т. Тощенко. М. : ЮНИТИ-ДАНА. С. 73.

Москвичев, Л. Н. (2009b) Знание (2) // Тезаурус социологии: темат. слов.-справ. / под ред Ж. Т. Тощенко. М. : ЮНИТИ-ДАНА. С. 77.

Мухаметзянова, Ф. Г., Мухаметзянова, Г. В. (2013) Образовательное знание как стратегия субъекта образовательной деятельности: размышления о новом понятии // Мир психологии. № 3. С. 95-107.

Немов, Р. С. (2003) Психология : в 3-х кн. / 4-е изд. М. : Владос. Кн. 1. Общие основы психологии. 688 с.

Рубинштейн, С. Л. (1989) Основы общей психологии : в 2 т. М. : Педагогика. Т. 2. 328 с.

Селиверстова, Н. А. (2015) Образовательный опыт как понятие социо- 
логии // Знание. Понимание. Умение. № 2. С. 79-87.

Щюц, А. (2004) Методология социальных наук // Избранное: Мир, светящийся смыслом. М. : РОССПЕН. 1056 с. С. 7-147.

Селиверстова Нина Анатольевна - доктор социологических наук, профессор, профессор кафедры социологии Московского гуманитарного университета. Адрес: 111395, Россия, г. Москва, ул. Юности, д. 5. Тел.: +7 (499) 374-60-21. Эл. адрес: nas0311@уа.ru

Seliverstova Nina Anatolievna, Doctor of Sociology, Professor, Department of Sociology, Moscow University for the Humanities. Postal address: 5 Yunosti St., 111395 Moscow, Russian Federation. Tel.: +7 (499) 374-60-21. E-mail: nas0311@ya.ru 